\title{
Author Correction: A chalcogenide-cluster-based semiconducting nanotube array with oriented photoconductive behavior
}

\author{
Jiaqi Tang (10), Xiang Wang (1D, Jiaxu Zhang, Jing Wang, Wanjian Yin (1), Dong-Sheng Li \& Tao Wu
}

Correction to: Nature Communications https://doi.org/10.1038/s41467-021-24510-0, published online 13 July 2021.

The author affiliation was missing for the first author (Jiaqi Tang) which resulted in the affiliation list being reordered as follows:

Jiaqi Tang1,2,5, Xiang Wang2,5, Jiaxu Zhang2,5, Jing Wang3, Wanjian Yin3, Dong-Sheng Li4 \& Tao Wu1,*

1 College of Chemistry and Materials Science, Guangdong Provincial Key Laboratory of Functional Supramolecular Coordination Materials and Applications, Jinan University, Guangzhou 510632, China.

2 College of Chemistry, Chemical Engineering and Materials Science, Soochow University, Suzhou 215123, China.

3 College of Energy, Soochow University, Suzhou 215006, China.

4 College of Materials and Chemical Engineering, Hubei Provincial Collaborative Innovation Centre for New Energy Microgrid, Key Laboratory of Inorganic Nonmetallic Crystalline and Energy Conversion Materials, China Three Gorges University, Yichang 443002, China.

5 These authors contributed equally: Jiaqi Tang, Xiang Wang, Jiaxu Zhang

* Correspondence and requests for materials should be addressed to T.W. (wutao@jnu.edu.cn).

These errors have been corrected in the PDF and HTML versions of the Article.

Published online: 12 August 2021

\footnotetext{
(c) (i) Open Access This article is licensed under a Creative Commons Attribution 4.0 International License, which permits use, sharing, adaptation, distribution and reproduction in any medium or format, as long as you give appropriate credit to the original author(s) and the source, provide a link to the Creative Commons license, and indicate if changes were made. The images or other third party material in this article are included in the article's Creative Commons license, unless indicated otherwise in a credit line to the material. If material is not included in the article's Creative Commons license and your intended use is not permitted by statutory regulation or exceeds the permitted use, you will need to obtain permission directly from the copyright holder. To view a copy of this license, visit http://creativecommons.org/licenses/by/4.0/.
}

(c) The Author(s) 2021 